\title{
A Bright Future for Biomedical Engineering
}

In this first of a series of Biomedical Engineering Society (BMES) presidential editorials, my intent is to share my vision for the Society and encourage the full engagement of its membership as stewards of the profession, to ensure the continued success of BMES and to meet societal goals.

Biomedical Engineering (BME) is the fastest growing engineering discipline with a projected employment growth of $72 \%$ by 2018 . Innovative technologies are being developed and medical advances are occurring at a rapid rate while global problems are increasing in complexity. In order to keep pace and meet challenges, biomedical engineering must train and develop the best talent and draw that talent from all sectors. BMES is uniquely positioned as a professional society to play an active role in leading the discipline and shaping the future of biomedical engineering. As $43^{\text {rd }}$ President of BMES, I have the privilege to provide leadership in engaging our members, constituents, agencies, institutions and other entities that share our vision of advancing human health and well-being. My vision is that the face of biomedical engineering is reflective of the society we serve and one that is inviting to all biomedical engineering sectors. Further, that as a field, we serve as the lead in driving medical innovation and discovery that translates to a better quality of life for all populations. To carry out this vision, foremost among my goals is to tap junior and underrepresented talent and prepare them as the future leaders of BME. I also seek to build partnerships across boundaries to build and sustain a professional community that ensures all members a sense of belonging and promotes a sense of responsibility to the profession. Success with these broader goals will allow BMES to continue on its current upward trajectory and cement its place as the world's leading society for biomedical engineering.

This is an exciting time for our field and for BMES. Since my initial involvement in BMES in the early 1990s we have experienced record growth and I have never seen the Society and its members more energized. There is much to be energized and excited about. We are in the best fiscal health ever, have the largest membership ever (over 6000 members strong) and are coming off of a record breaking annual meeting. At our 2012 Annual Meeting, recently held in Atlanta and hosted by Georgia Tech and Emory University, nearly 4000 attendees took advantage of excellent scientific programming, expanded programming in professional development, career planning and K-12 student outreach, new programming related to health disparities and inequities, and programming sponsored by both the National Institute of Biomedical Imaging and Bioengineering (NIBIB) of $\mathrm{NIH}$ and the Coulter Foundation. We welcomed the first student chapter from a Historically Black College or University, North Carolina A\&T, and we provided some of the best networking opportunities to date, including the Bash at the Atlanta Aquarium. Our job now in the coming year is to seize the moment, build on our successes and capitalize on the energy and excitement that has been generated as we implement our strategic plan through the full engagement of our membership.

Looking back on our past history, consider that BMES was established in 1968 and the first BMES Annual Meeting was held November 18-20, 1968 in Houston TX, in conjunction with the 21st Annual Conference on Engineering in Medicine and Biology (later to become the Alliance for Engineering in Medicine and Biology (AEMB)). Among the attendees of the first Annual Meeting were some of the 83 founding and 178 charter members. In 1990, the first free standing BMES Annual Meeting, held October 21-24, was hosted by Virginia Tech in Blacksburg, VA and had 109 attendees. In subsequent years, BMES out grew the campus venue for holding meetings and now in 2012 has outgrown the model of having institutions serve as meeting hosts and is moving to a national model. As with the annual meeting, a number of areas have experienced significant growth and new configurations. We now publish three journals and a monthly electronic newsletter, we established our first Special Interest Group (SIG), Cellular and Molecular Bioengineering, we have taken on Biomedical Engineering Career Connections (formerly known as the Career Alliance) and we are working on new regional and national models for industry and international partnerships, activities and services.

Throughout the years since its inception, BMES leadership and its members have grappled with recurrent themes and challenges like annual meeting revenue (due to a meetings-driven budget), how to increase membership, publications, awards and how to better interact with industry. These themes are common to all 
professional societies given their educational and informational missions typically carried out through publishing journals, bestowing awards, raising awareness and arranging conferences. They are best dealt with by striving for excellence and innovation and by providing opportunities for members and partners to be engaged in Society activities. My goal is to tap into existing and previously underrepresented talent to devise new and transformative approaches to recurrent challenges while staking out new territories for the Society. Among these new or emerging territories for BMES are education and outreach, advocacy, and global outreach.

In recognition of the 35th anniversary of the founding of BMES, BMES historian, Paul Fagette interviewed all of the past presidents from 1968 to 2003 . The past presidents primarily reflected on their term as president and shared with Paul what they thought they had accomplished along with their hopes for the Society. Thomas Skalak, president from 1999 to 2000 shared, "...my greatest hope was to help encourage new students, new corporate members, and new colleagues to feel a sense of belonging - to consider the Biomedical Engineering Society their home society...in the sense that the Biomedical Engineering Society is a place where the work of the BME discipline gets done and where a series of memorable and life-changing events are possible." A sense of home and place and of belonging is what I believe all individuals in our profession seek, is what is our responsibility to provide, and is critical to my vision of our being reflective of the society we serve. My greatest hope is that when Paul Fagette interviews me for the 50th anniversary of the founding of BMES, I will be able to reflect back and see my vision taking shape and to see the fruits of BMES' achievements in preparing the next generation of biomedical engineers and in advancing human health and well-being through innovation driven by diversity.

I can't overemphasize the power of member engagement in moving the Society forward and in contributing to one's personal career development. While serving as Chair of the Membership Committee, Kyriacos Athanasiou approached me to serve as a committee member and that marked my first formal engagement with BMES through service to the Society. I went on to serve as an elected member of the Board of Directors, 1997-2000, the first elected Treasurer, 2005-2009, founder and member of the Diversity Committee since 2008, Chair of the Finance Committee, 2010-2011, President-elect, 2011-2012, and President, 2012-2014.
Kyriacos Athanasiou, who served as BMES President 2003-2004, Thomas Skalak, other past presidents and myself, all understand that BMES is only as strong as the people who comprise its membership and volunteer their time and expertise to work hand-in-hand with colleagues and with the BMES staff. These leaders understand that in order to remain true to the description of BMES, coined by past president Eric Gilbeau (1998-1999), as "The Full Service Professional Society for Biomedical Engineering and Bioengineering," BMES must be inclusive, must create a sense of belonging, must promote excellence and innovation and must fully embrace diversity. Scott Page, author of "The Difference: How the Power of Diversity Creates Better Groups, Firms, Schools and Societies," espouses that the untapped potential of diversity must be harnessed in order to maximize progress and innovation. By serving as a change agent to sustain and promote opportunities, BMES is poised to do just that for the benefit of the discipline, the nation and the world.

My challenge to our leaders and members is simple: Get involved! We are all stewards of our discipline and responsible for its future and well-being and to meet our responsibilities, we all need to be fully engaged in carrying out the mission of BMES.

I express thanks to outgoing President, Rick Waugh, the BMES Board, annual meeting organizers, BMES members, BMES staff and all those who support our Society. I welcome current and future members and look forward to unparalleled achievements in the coming years.

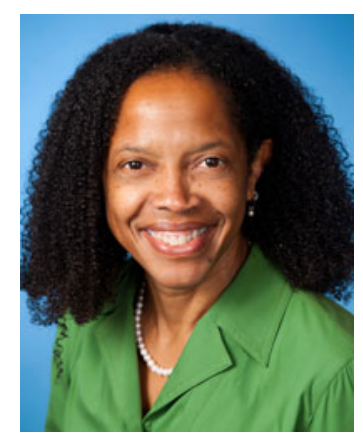

Gilda BARABino

The Wallace H. Coulter Department of Biomedical Engineering Georgia Institute of Technology and Emory University

Electronic mail: barabino@gatech.edu 